Pacific Journal of Mathematic 


\title{
A RECIPROCITY LAW FOR RAMANUJAN SUMS
}

\author{
KENNETH R. JOHNSON
}

\begin{abstract}
Certain arithmetic functions are representable by two types of series involving Ramanujan sums. A reciprocity law for Ramanujan's sum is derived which relates these series.
\end{abstract}

Ramanujan [7] and Hardy [4] found representations for several arithmetric functions of $n$, of the form

$$
F(n)=\sum_{k=1}^{\infty} a(k) c_{k}(n),
$$

where $c_{k}(n)$ is Ramanujan's sum. Rearick [8] showed that such representations exist for a large class of arithmetic functions, and called them $C$-series representations. In this paper we show that functions of a certain class are also representable as series of the form

$$
F(k)=\sum_{n=1}^{\infty} b(n, k) c_{k}(n) .
$$

Let us call representations like (2) $C^{\prime}$-series. The class of functions represented by $C^{\prime}$-series is smaller than the class of functions representable by $C$-series; however we can use a reciprocity law for Ramanujan sums to show that (1) and (2) are equivalent under certain conditions.

Ramanujan proved

$$
c_{k}(n)=\sum_{d \mid(k, n)} d \mu(k / d) .
$$

Rearick and Donovan [3] showed that for fixed square-free $k$, the function $\mu(k) c_{k}(n)$ is multiplicative in $n$. After this observation it is easy to prove

Lemma 1. For fixed square-free $k$,

$$
\mu(k) c_{k}(n)=\sum_{d \backslash k, n)} d \mu(d) .
$$

Proof. We need only show that the right hand side of (4) is multiplicative and then demonstrate the equality when $n$ is a power of a prime.

DEFINITION 2. Let $\bar{k}$ denote the largest square-free divisor of 
$k$ (the core of $k$ ), and let $k^{*}=k / \bar{k}$.

Hardy [4] proved that $c_{k}(n)=0$ unless $k^{*} \mid n$. Using this fact, one may work directly from (3) to prove

\section{LEMMA 3. $c_{k}\left(n k^{*}\right)=k^{*} c_{\bar{k}}(n)$.}

THEOREM 4. Let $F$ be an arithmetic function. Let $A(k)$ be the function which is zero whenever $k$ is not square-free, and for squarefree values of $k$ is defined recursively by the equation

$$
F(k)=\sum_{a \mid k} d \mu(d) A(d) .
$$

Suppose

$$
\sum_{k=1}^{\infty} \sum_{n=1}^{\infty}|A(k n)|<\infty
$$

Define

$$
b(k)=\sum_{n=1}^{\infty} \mu(n) A(n k) .
$$

Then

$$
\mu(k) F(k)=\sum_{n=1}^{\infty} b(n) c_{k}(n),
$$

for all square-free $k$, and this series converges absolutely. On the other hand, if $F$ has a series representation like (8) with $\sum_{k=1}^{\infty}|b(k)|<\infty$, and $b(k)=0$ if $k$ is not square-free, then the coefficient function is given by (7).

Proof. Using a well known inversion property of the Möbius function ([5, Theorem 270]),

$$
A(k)=\sum_{n=1}^{\infty} b(n k) \text {. }
$$

Using this in (5) we obtain

$$
\begin{aligned}
F(k) & =\sum_{a \mid k} d \mu(d) \sum_{n=1}^{\infty} b(n d) \\
& =\sum_{n=1}^{\infty} b(n) \sum_{d \backslash k, n)} d \mu(d) \\
& =\sum_{n=1}^{\infty} b(n) c_{k}(n) \mu(k), \quad \text { by Lemma } 1
\end{aligned}
$$

since $k$ is square-free. So $\mu(k) F(k)=\sum_{n=1}^{\infty} b(n) c_{k}(n)$. The absolute convergence of (8) follows from (6). 
On the other hand, given (8) with $b(k)=0$ for all non squarefree $k$, and $\sum_{k=1}^{\infty}|b(k)|<\infty$, we can reverse the steps to obtain (9), which after (6) is equivalent to (7), so the coefficient function is uniquely determined.

The restriction of the argument of the coefficient function to the square-free integers is necessary for uniqueness. For example, if we expand $\sum_{n=1}^{\infty}\left(\mu(k) c_{k}(n) / n^{s}\right)$ and $\sum_{n=1}^{\infty}\left(|\mu(n)| \mu(k) c_{k}(n) / \varphi_{s}(n)\right)$ in Euler products $(s=\sigma+$ it) for $\sigma>1$ we find

$$
\varphi_{s-1}(k)=\frac{\mu(k) k^{s-1}}{\zeta(s)} \sum_{n=1}^{\infty} \frac{c_{k}(n)}{n^{s}}
$$

and also

$$
\varphi_{s-1}(k)=\frac{\mu(k) k^{s-1}}{\zeta(s)} \sum_{n=1}^{\infty} \frac{|\mu(n)| c_{k}(n)}{\varphi_{s}(n)},
$$

for any square-free value of $k$ (see [6]). Here $\varphi_{s}(k)=k^{s} \Pi_{p \mid k}\left(1-\left(1 / p^{s}\right)\right)$. Since the sum in Lemma 1 is symmetric in $k$ and $n$, we have

Lemma 5. For all square-free $k$ and $n$,

$$
\mu(k) c_{k}(n)=\mu(n) c_{n}(k) .
$$

We may now obtain the general reciprocity law for Ramanujan sums.

THEOREM 6. For all $k$ and $n$,

$$
\frac{\mu(\bar{k})}{k^{*}} c_{k}\left(n k^{*}\right)=\frac{\mu(\bar{n})}{n^{*}} c_{n}\left(k n^{*}\right) \text {. }
$$

Proof. By Lemma 5, $\mu(\bar{k}) c_{\bar{k}}(\bar{n})=\mu(\bar{n}) c_{\bar{n}}(\bar{k})$. From (3) it follows that $c_{\bar{k}}(\bar{n})=c_{\bar{k}}(n)$, so $\mu(\bar{k}) c_{\bar{k}}(n)=\mu(\bar{n}) c_{\bar{n}}(k)$. Upon application of Lemma 3 to both sides of this equation the reciprocity law is proved.

Using the reciprocity law for Ramanujan sums, we can show that $C^{\prime}$-series exist which represent certain functions for all integral values of their argument. However, in these representations the coefficient function becomes dependent on both variables. These $C^{\prime}$ series representations are equivalent to a class of $C$-series representations.

THEOREM 7. A function $F$ has an absolutely convergent $C$-series representation $F(n)=\sum_{k=1}^{\infty} a(k) c_{k}(n)$, with $a(k)=0$ if $k$ is not squarefree, if and only if $F(n) n^{*} \mu(\bar{n})$ has an absolutely convergent $C^{\prime}$-series representation $F(n) n^{*} \mu(\bar{n})=\sum_{k=1}^{\infty} b\left(k / n^{*}\right) c_{n}(k)$. 
Proof. Suppose $F(n)=\sum_{k=1}^{\infty} a(k) c_{k}(n)$ is absolutely convergent and $a(k)=0$ if $k$ is not square-free. Then

$$
\begin{aligned}
F(n) & =\sum_{k=1}^{\infty} a(k) c_{k}(n) \\
& =\sum_{k=1}^{\infty} \mu(k) a(k) \mu(k) c_{k}(n), \quad \text { since } k \text { is square-free } \\
& =\sum_{k=1}^{\infty} \mu(k) a(k) \frac{\mu(\bar{n})}{n^{*}} c_{n}\left(k n^{*}\right), \quad \text { by reciprocity } \\
& =\frac{\mu(\bar{n})}{n^{*}} \sum_{k=1}^{\infty} b(k) c_{n}\left(k n^{*}\right), \quad \text { where } b(k)=\mu(k) a(k) \\
& =\frac{\mu(\bar{n})}{n^{*}} \sum_{n=1}^{\infty} b\left(k / n^{*}\right) c_{n}(k) .
\end{aligned}
$$

Conversely,

$$
\begin{aligned}
F(n) & =\frac{\mu(\bar{n})}{n^{*}} \sum_{k=1}^{\infty} b\left(k / n^{*}\right) c_{n}(k) \\
& =\frac{\mu(\bar{n})}{n^{*}} \sum_{k=1}^{\infty} b(k) c_{n}\left(k n^{*}\right) \\
& =\sum_{k=1}^{\infty} \frac{b(k) \mu(\bar{k})}{k^{*}} c_{k}\left(n k^{*}\right), \quad \text { by reciprocity } \\
& =\sum_{k=1}^{\infty} \alpha(k) c_{k}\left(n k^{*}\right), \quad \text { where } \alpha(k)=\frac{b(k) \mu(\bar{k})}{k^{*}} \\
& =\sum_{k=1}^{\infty} \alpha(k) k^{*} c_{\bar{k}}(n), \quad \text { by Lemma } 3 .
\end{aligned}
$$

If we now let $H(k)=\left\{m \in Z^{+}: \bar{m}=k\right\}$ and put

$$
a(k)=\sum_{m \in H(k)} m^{*} \alpha(m)
$$

(this converges since the original sum converged absolutely), then

$$
F(n)=\sum_{k=1}^{\infty} a(k) c_{k}(n),
$$

with $a(k)=0$ if $k$ is not square-free.

For example, in [7] Ramanujan proved

$$
\varphi_{s-1}(n)=\frac{n^{s-1}}{\zeta(s)} \sum_{k=1}^{\infty} \frac{\mu(k) c_{k}(n)}{\varphi_{s}(k)} .
$$

If we now apply the reciprocity law to (10) we obtain

$$
\varphi_{s-1}(n)=\frac{n^{s-1} \mu(\bar{n})}{\zeta(s) n^{*}} \sum_{k=1}^{\infty} \frac{\left|\mu\left(k / n^{*}\right)\right| c_{n}(k)}{\varphi_{s}\left(k / n^{*}\right)},
$$

which is a $C^{\prime}$-series representation of $\varphi_{s-1}$. This representation is 
now valid for all $n$, generalizing our earlier result for $\varphi_{s-1}$.

Following Anderson and Apostol [1], we turn our attention to a generalized Ramanujan sum, defined as follows.

Definition 8. For any two arithmetic functions $f$ and $g$ let $s_{k}(n)=\sum_{d \backslash(k, n)} f(d) g(k / d)$.

THEOREM 9. Suppose $f$ and $g$ are multiplicative and $g(n)= \pm 1$ for all $n$. Then for fixed $n$ the function $s_{k}(n)$ is multiplicative in the variable $k$, while for fixed $k$ the function $g(k) s_{k}(n)$ is multiplicative in the variable $n$.

Proof. The first assertion is easy and requires only that $f$ and $g$ be multiplicative (see [2, Lemma 2.1]). To prove the second assertion, fix $k$ and choose $(n, m)=1$. We have

$$
g(k) s_{k}(m) g(k) s_{k}(n)=s_{k}(m) s_{k}(n),
$$

since $g^{2}(k)=1$. Both sides of (11) are multiplicative in $k$ so we may assume $k$ is a prime power. Then

$$
s_{k}(m) s_{k}(n)=\sum_{d_{1} \mid(k, m)} f\left(d_{1}\right) g\left(k / d_{1}\right) \sum_{d_{2} \backslash\langle k, n)} f\left(d_{2}\right) g\left(k / d_{2}\right) .
$$

Since $(m, n)=1$ and $k$ is a prime power, either $d_{1}$ or $d_{2}$ must be 1 , so

$$
g\left(k / d_{1}\right) g\left(k / d_{2}\right)=g(k) g\left(k / d_{1} d_{2}\right)
$$

and thus

$$
\begin{aligned}
s_{k}(m) s_{k}(n) & =\sum_{d_{1} d_{2} \backslash(k, m)} f\left(d_{1} d_{2}\right) g(k) g\left(k / d_{1} d_{2}\right) \\
& =g(k) \sum_{d\lfloor(k, m))} f(d) g(k / d) \\
& =g(k) s_{k}(m n),
\end{aligned}
$$

thus establishing the theorem.

In order to obtain a satisfactory reciprocity law for $s_{k}(n)$, we must now either restrict $k$ and $n$ to the square-free integers, or restrict $g$ to the class of completely multiplicative functions. We choose the latter course.

LEMma 10. Suppose $f$ is multiplicative, g completely multiplicative, and $g(n)= \pm 1$ for all $n$. Then

$$
g(k) s_{k}(n)=\sum_{d \mid(k, n)} f(d) g(d) .
$$


Proof.

$$
\begin{aligned}
g(k) s_{k}(n) & =g(k) \sum_{d \mid(k, n)} f(d) g(d) \\
& =g(k) \sum_{d \mid(k, n)} f(d) \frac{g(k)}{g(d)}
\end{aligned}
$$

since $g_{!}$is completely multiplicative,

$$
=\sum_{d \mid(k, n)} f(d) g(d)
$$

since $g(n)= \pm 1$ for all $n$.

Under our assumptions on $f$ and $g$, the reciprocity law for $s_{k}(n)$ is somewhat simpler than that for $c_{k}(n)$, namely:

THEOREM 11. With the hypotheses of Lemma 10,

$$
g(n) s_{n}(k)=g(k) s_{k}(n) .
$$

Proof. The sum in Lemma 10 is unchanged if we interchange $k$ and $n$.

Fnally, using the same proof as for Theorem 4, we can derive general series expansions of certain arithmetic functions in terms of either variable of $s_{k}(n)$, and the expansions are equivalent due to reciprocity. We have

THEOREM 12. Let $F, f$, and $g$ be arithmetic functions, with: $f$ and $g$ satisfying the hypotheses of Lemma 10 . Let $A(n)$ be the function which is zero whenever $f(n)=0$, and for other values of $n$ is defined recursively by the equation $F(n)=\sum_{d \mid n} f(d) g(d) A(d)$. Suppose

$$
\sum_{k=1}^{\infty} \sum_{n=1}^{\infty}|A(k n)|<\infty
$$

Also define

$$
b(n)=\sum_{k=1}^{\infty} A(k n) \mu(k)
$$

and

$$
a(n)=g(n) b(n) .
$$

Then for all $n$ such that $f(n) \neq 0$,

$$
F(n)=\sum_{k=1}^{\infty} a(k) s_{k}(n)
$$

and 


$$
g(n) F(n)=\sum_{k=1}^{\infty} b(k) s_{n}(k)
$$

where both sums converge absolutely. On the other hand, if $a(n)$ or $b(n)$ is the coefficient function in a series of the form (15) or (16) representing $F$ whose associated function $A$ satisfies (12), with $\sum_{n=1}^{\infty}|a(n)|<\infty$, and $A(n)=0$ if $f(n)=0$, then the coefficient functions are given by (13) and (14).

For example, if we let $s_{k}(n)=\sum_{d \mid(k, n)} \mu(d) \lambda(k / d)$, we can expand $\sum_{k=1}^{\infty}\left(\mu(k) s_{k}(n) / \varphi_{s}(k)\right)$ in an Euler product for $\sigma>1$, and obtain (for all square-free $n$ )

$$
\sigma_{s}(n)=\frac{n^{s}}{\zeta(s)} \sum_{k=1}^{\infty} \frac{\mu(k) s_{k}(n)}{\varphi_{s}(k)} .
$$

$\left(\sigma_{s}(n)\right.$ is the sum of the sth powers of the divisors of $\left.n.\right)$

In light of reciprocity and the fact that $|\mu(k)|=\mu(k) \lambda(k)$, we may also write

$$
\lambda(n) \sigma_{s}(n)=\frac{n^{s}}{\zeta(s)} \sum_{k=1}^{\infty} \frac{|\mu(k)| s_{n}(k)}{\varphi_{s}(k)}
$$

\section{REFERENCES}

1. D. R. Anderson and T. M. Apostol, The evaluation of Ramanujan's sum and generalizations, Duke Math. J., 20 (1952), 211-216.

2. J. Chidambaraswamy, Generalized Ramanujan's sum, Periodica Mathematica Hungarica, 10 (1979), 71-88.

3. G. S. Donovan and D. Rearick, On Ramanujan's sum, Det Kgl. Norske Vidensk Selsk. Fordhandlinger, 39 (1966), 1-2.

4. G. H. Hardy, Note on Ramanujan's trigonometrical function $c_{q}(n)$, and certain series of arithmetrical functions, Cambridge Philosophical Society Proceedings, 20 (1921), 263-271.

5. G. H. Hardy and E. M. Wright, An Introduction to the Theory of Numbers, Oxford 1960.

6. K. Johnson, Reciprocity and Multiplicativity in a Class of Arithmetic Functions, $\mathrm{Ph}$. D. Thesis, University of Colorado, (1980).

7. S. Ramanujan, On certain trigonometrical sums and their applications in the theory of numbers, Cambridge Philosophical Transactions, 22 (1918), 259-276.

8. D. Rearick, Semi-multiplicative functions, Duke Math. J., 33 (1966), 49-53.

Received January 14, 1980 and in revised form June 23, 1980.

NoRTh DAKOTA

FARGO, ND 58105 



\title{
PACIFIC JOURNAL OF MATHEMATICS
}

\section{EDITORS}

\author{
DONALD BABBITT (Managing Editor) \\ University of California \\ Los Angeles, CA 90024 \\ Hugo RossI \\ University of Utah \\ Salt Lake City, UT 84112 \\ C. C. Moore and ANDrew OGG \\ University of California \\ Berkeley, CA 94720
}

\section{J. DugundjI}

Department of Mathematics

University of Southern California

Los Angeles, CA 90007

R. FinN and J. Milgram

Stanford University

Stanford, CA 94305

\section{ASSOCIATE EDITORS}
R. ARENS
E. F. BeCKENBACH
B. H. NeUMANN
F. WOLF
K. YoshidA

\section{SUPPORTING INSTITUTIONS}

UNIVERSITY OF ARIZONA

UNIVERSITY OF BRITISH COLUMBIA

CALIFORNIA INSTITUTE OF TECHNOLOGY

UNIVERSITY OF CALIFORNIA

MONTANA STATE UNIVERSITY

UNIVERSITY OF NEVADA, RENO

NEW MEXICO STATE UNIVERSITY

OREGON STATE UNIVERSITY

\author{
UNIVERSITY OF OREGON \\ UNIVERSITY OF SOUTHERN CALIFORNIA \\ STANFORD UNIVERSITY \\ UNIVERSITY OF HAWAII \\ UNIVERSITY OF TOKYO \\ UNIVERSITY OF UTAH \\ WASHINGTON STATE UNIVERSITY \\ UNIVERSITY OF WASHINGTON
}

The Supporting Institutions listed above contribute to the cost of publication of this Journal, but they are not owners or publishers and have no responsibility for its content or policies.

Mathematical papers intended for publication in the Pacific Journal of Mathematics should be in typed form or offset-reproduced, (not dittoed), double spaced with large margins. Please do not use built up fractions in the text of the manuscript. However, you may use them in the displayed equations. Underline Greek letters in red, German in green, and script in blue. The first paragraph or two must be capable of being used separately as a synopsis of the entire paper. Please propose a heading for the odd numbered pages of less than 35 characters. Manuscripts, in triplicate, may be sent to any one of the editors. Please classify according to the scheme of Math. Reviews, Index to Vol. 39. Supply name and address of author to whom proofs should be sent. All other communications should be addressed to the managing editor, or Elaine Barth, University of California, Los Angeles, California, 90024.

50 reprints to each author are provided free for each article, only if page charges have been substantially paid. Additional copies may be obtained at cost in multiples of 50 .

The Pacific Journal of Mathematics is issued monthly as of January 1966. Regular subscription rate: $\$ 102.00$ a year (6 Vols., 12 issues). Special rate: $\$ 51.00$ a year to individual members of supporting institutions.

Subscriptions, orders for numbers issued in the last three calendar years, and changes of address shoud be sent to Pacific Journal of Mathematics, P.O. Box 969, Carmel Valley, CA 93924, U.S.A. Old back numbers obtainable from Kraus Periodicals Co., Route 100, Millwood, NY 10546.

PUBLISHED BY PACIFIC JOURNAL OF MATHEMATICS, A NON-PROFIT CORPORATION

Printed at Kokusai Bunken Insatsusha (International Academic Printing Co., Ltd.). 8-8, 3-chome, Takadanobaba, Shinjuku-ku, Tokyo 160, Japan. 


\section{Pacific Journal of Mathematics}

\section{Vol. 98, No. 1 \\ March, 1982}

Humberto Raul Alagia, Cartan subalgebras of Banach-Lie algebras of

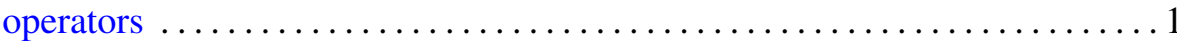

Tom M. (Mike) Apostol and Thiennu H. Vu, Elementary proofs of

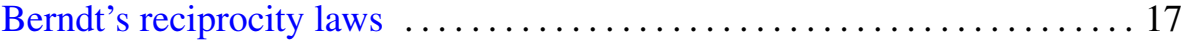

James Robert Boone, A note on linearly ordered net spaces $\ldots \ldots \ldots \ldots . \ldots 25$

Miriam Cohen, A Morita context related to finite automorphism groups of

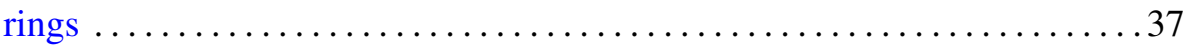

Willibald Doeringer, Exceptional values of differential polynomials . . . . . . 55

Alan Stewart Dow and Ortwin Joachim Martin Forster, Absolute

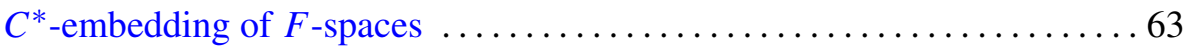

Patrick Hudson Flinn, A characterization of $M$-ideals in $B\left(l_{p}\right)$ for

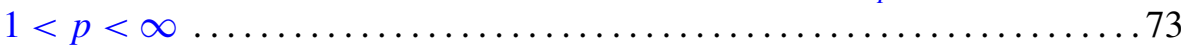

Jack Emile Girolo, Approximating compact sets in normed linear spaces . . . 81

Antonio Granata, A geometric characterization of $n$th order convex

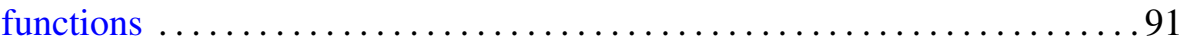

Kenneth Richard Johnson, A reciprocity law for Ramanujan sums . . . . . . .99

Grigori Abramovich Kolesnik, On the order of $\zeta\left(\frac{1}{2}+i t\right)$ and $\Delta(R) \ldots \ldots 107$

Daniel Joseph Madden and William Yslas Vélez, Polynomials that

represent quadratic residues at primitive roots $\ldots \ldots \ldots \ldots \ldots \ldots \ldots 123$

Ernest A. Michael, On maps related to $\sigma$-locally finite and $\sigma$-discrete

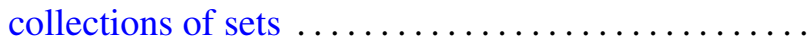

Jean-Pierre Rosay, Un exemple d'ouvert borné de $\mathbf{C}^{3}$ “taut" mais non

hyperbolique complet

Roger Sherwood Schlafly, Universal connections: the local problem

Russel A. Smucker, Quasidiagonal weighted shifts .....

Eduardo Daniel Sontag, Remarks on piecewise-linear algebra . .

Jan Søreng, Symmetric shift registers. II

H. M. (Hari Mohan) Srivastava, Some biorthogonal polynomials suggested

by the Laguerre polynomials 